NASATEGHNICAL

MEMORANDUM

NASA TM X-52265

MEMORANDUM

N $67-16045$

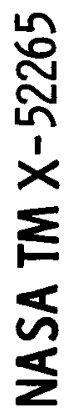
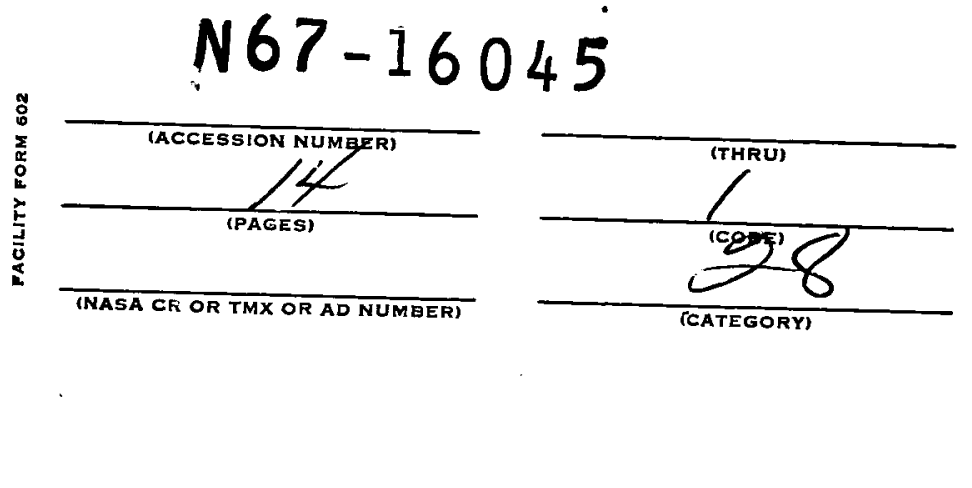

\title{
A THERMODYNAMIC FLOW ANALYSIS OF PARTICLE FORMATION EFFICIENCY IN A MIXED FLOW COLLOID THRUSTOR
}

GPO PRICE \$

by Daniel S. Goldin

CFSTI PRICE(S) \$

Lewis Research Center

Cleveland, Ohio

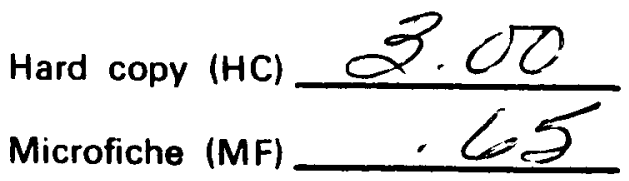

TECHNICAL PAPER proposed for presentation at H 653 July 65 Fifth Acrospace Sciences Meeting sponsored by

1 American Institute of Aeronautics and Astronautics January 23-27, 1967 
Lewis Research Center

Cleveland, Ohio 


\section{A THERMODYNAMIC FLOW ANALYSIS OF PARTICLE FORMATION EFFICIENCY IN A MIXED FLOW COLLOID THRUSTOR \\ by Daniel S. Goldin \\ Lewis Research Center \\ National Aeronautics and Space Administration \\ Cleveland, Ohio}

\section{ABSTRACT}

The feasibility of adding a coolant gas to the nozzle flow of a colloid thrustor to improve the particle formation efficiency is examined. The study is based upon a thermodynamic analysis of the nozzle flow, where a simple physical model is used to describe the energy balance of the condensation process. The noncondensable coolant gas provides an additional heat sink for the latent heat given up during condensation. In cases applicable to colloid thrustors, the analysis indicated maximum efficiencies of about 80 percent using very optimistic assumptions. The analysis also showed that there is an optimum fractional mass flow of coolant gas that maximizes the particle formation efficiency. Finally because of boundary layer and non-continuum flow effects in the nozzle, the minimum allowable nozzle exit pressure is about 0.1 torr, while at the same time, because of space charge effects in the accelerator, the maximum allowable nozzle exit pressure is limited to about 0.01 torr. Since these conditions are mutually exclusive, unique flow schemes appear necessary if a mixed-flow condensation-type colloid thrustor is to be of practical value.

\section{INTRODUCTION}

This andiysis is ar extonsion of one presented in reference 1 . In that analysis, in which only a condensable vapor was used in a condensation-type colloid thrustor, the particle formation efficiency was found to be less than $50 \%$ even under the most favorable conditions. As shown in reference 2 , colloid thrustors should operate with an overall efficiency of better than 50\% in the 2000-5000 second specific impulse range to be useful in electric propulsion. In reference 1 it was found that the main factor preventing higher formation efficiencies was the absence of an adequate heat sink to absorb the latent heat of condensation. Tt, was suggested by the authors of reference 3 that the addition to the flow of a noncondensable coolant gas should significantly increase the particle formation efficiency. It was therefore the purpose of this analysis to determine if the application of this technique would result in particle formation efficiencies of $50 \%$ or greater for a colloid thrustor at realistic operating points.

Over the past few years, a number of investigations have been conducted to evaluate the particle formation efficiency of a mixed flow condensation process (refs. 4 to 6 ). These approaches have been quite useful in developing a qualitative understanding of the condensation problem, but they have been of little help in the prediction of quantitative limits for particle formation efficiency as applied to a colloid thrustor.

Many of the analytical difficulties of the aforementioned approaches are avoided by basing the mathematical description on an overall energy balance instead of details of the condensation process. Such a balance is obtained from the energy exchanges between the vapor, coolant gas and condensed particles. In this approach the latent heat rejected by vapor condensation is absorbed by several energy sinks in the system. These sinks for realistic thrustors are:

(1) the thermal energy of the coolant gas,

(2) the volume energy of the con= densed particles,

(3) the directed translational energy of the stream,

(4) the thermal energy of the uncondensed vapor in the stream.

To further simplify the analysis, the condensable vapor is assumed to remain in a saturated state during the condensation process. This condition does not appear to be too far from physical reality for a number of propellants in light of the experimental data of references 5 and 7 .

\section{PHYSICAL MODEL}

A schematic diagram of the colloid thrustor analyzed herein is shown in figure 1. A mixture of condensable vapor and noncondensable coolant gas is injected into a stagnation chamber where it is heated before being expanded in an adiabatic axisymmetric supersonic nozzle. During expansion, the vapor condenses to form small particles which, for a colloid thrustor, should be about $10^{5}$ atomic mass units per particle (ref. 8). The particles then pass into the charging chamber. (The charging may take place by electron attachment as indicated in figure 1.) Then the negatively charged particles are electrostatically accelerated from a negative thrustor potential to a potential slightly higher than that of free space. Finally the beam is neutralized and approaches space potential. The noncondensable gas and any uncondensed propellant are lost to space in this concept.

The overall thrustor efficiency is the product of the efficiencies associated with each of these processes (ref. 8 ). Associated with the nozzle condensation process is the particle formation efficlency, which is defined as the ratio of the condensed particle mass flow rate to 
the total mass flow rate. This study is concerned only with the particle formation efficiency and the constraints placed upon it by the performance requirements of certain components in the thrustor system. A schematic description of the physical model used for the particle formation process is shown in figure 2. A mixture of vapor and coolant gas is heated in the stagnation chamber to some superheated state relative to the condensable vapor. The mixture is then expanded isentropically until a saturated state is reached for the condensable vapor. In this analysis, both the location of the saturation point, station 1 , and its corresponding value of superheat required in the stagnation chamber, station 0 , are fixed by specifying the value of the free stream Mach number at the saturation point. $\mathrm{M}_{\mathrm{S}}$. The nozzle expansion process from station 0 to station 1 is called region $I$ of the particle formation process. This part of the expansion is shown as a solid line in both the temperature and pressure graphs. The form of the equations describing the flow process in region I are the same as those for the isentropic expansion of a single gaseous component (ref. 9). The equation for the specific heat ratio and molecular weight of the mixture, however, can be written in a form similar to that of reference 9 as,

$$
\Gamma=\gamma_{V}\left[\frac{\frac{\gamma_{n}}{\gamma_{V}}\left(\frac{\gamma_{V}-1}{\gamma_{n}-I}\right) f \alpha+1-f}{\left(\frac{\gamma_{V}-1}{\gamma_{n}-1}\right) f \alpha+1-f}\right]
$$

and

$$
\boldsymbol{\mu}=\frac{\hat{\boldsymbol{t}}_{\mathrm{v}}}{1-\mathrm{f}+\mathrm{f} \alpha}
$$

All symbols are defined in appendix $A$.

Expansion of the stream beyond station 1 results in condensation of the vapor phase. The maximum amount of condensation for a continuous condensation process occurs for an equilibrium saturated expansion of the condensable vapor. This condition is used to determine the stream temperature-pressure relation. The total heat capacity of the stream then governs the amount of propellant that will condense at any point in the nozzle. The experimental data of references 5 and 7 indicate that it is possible for the vapor phase in a mixed flow nozzle condensation process to approach the conditions of a saturated expansion. It is also indicated in reference 7 that the amount of material that actually condensed was slightly less than the saturated value.

The saturated expansion condensation process is considered to continue until the vapor phase becomes depleted or, until the flow leaves the nozzle. For the purpose of this analysis, vapor phase depletion is considered to have taken place when the mass flow rate of the remaining "uncondensed" vapor is equal to only $1 \%$ of the total mass flow rate. Sample calculations indicate that an order of magnitude variation of this limit would not significantly affect the overall results of this analysis. The saturated expansion from station 1 to station 2 is called region II of the particle formation process. The stream static temperature and pressure profiles are shown as dashed lines in this region in figure 2. Shown also for comparison, is a continuation of the initial isentropic expansion process from region I.

Once the cutoff condition for the condensation process is reached at station 2 , it is assumed that any further expansion takes place isentropically until the nozzle exit pressure is reached. As will be discussed later, the choice of the nozzle exit pressure must be compatible with the values required by the thrustor system operating restrictions.

The portion of the nozzle expansion process from station 2 to station 3 is called region III. In region III, the isentropic expansion lowers the stream pressure and cools the condensed particles. The calculation is terminated wherever. stream pressure equals the preset value of nozzle exit pressure. It is assumed that no further condensation or stream expansion takes place beyond the nozzle exit. If a free expansion is considered beyond the nozzle exit, the condensed particle beam will probably become depleted of coolant gas and residual vapor in a short distance downstream of the nozzle exit due to the relatively high random velocity and low density of these species. Expansion of the condensed particle beam itself does not appear too feasible since the ratio of the random to directed velocity of the condensed particles is relatively low. To collect and recinculate both the condensable vapor and coolant gas would be quite a formidable task for the operating conditions of interest. Therefore for the purposes of this analysis, all the residual vapor and coolant gas are rejected to space. Only the particle beam enters the charging chamber.

To keep the analysis physically realistic but analytically tractable, several simplifying assumptions are made. The flow is assumed to be one dimensional. Also it is assumed that a negligible amount of heat is transferred across the boundary layer. This physical model appears to be in agreement with the data presented in reference 10, in which stagnation and nozzle exit pressures similar to those of interest in this analysis ( 10 to 0.01 torr) were considered. In addition, it was shown in reference 1 that for operating conditions of interest to a condensation-type colloid thrustor, drop cooling by thermal radiation is negligible. Therefore, the entire nozzle expansion process can be considered to take place adiabatically. Finally it is assumed that there is negligible condensation on the nozzle walls so that continuity of mass flow is maintained in the stream itself. 
In this section, expressions for the stream properties in region II are obtained in terms of the initial conditions in the stagnation chamber and the propellant properties.

\section{Stream Temperature-Pressure Relation}

As discussed in the physical model section, the stream properties are controlled by the fact that the condensable vapor expands in a saturated state. The most common method of expressing the temperature vapor pressure relation, is by the Clausius-Clayperon equation

$$
\frac{d p_{V}}{d T}=\frac{L}{\boldsymbol{C}_{V}}-\frac{p_{V}}{T}
$$

An expression for $p_{V}$ in terms of the stream properties can be obtained by using Dalton's law of partial pressures with the equation of state and the continuity equation. Three simplifying assumptions are made. First, the partial pressure exerted by the condensed particle gas is assumed to be negligible. Secondly, both vapor and coolant gases are treated as perfect gases. Since the pressure range of interest is relatively low, the compressibility factor for both condensable vapor and coolant gas is very close to unity. Thirdly, it is assumed that all species have the same directed velocity and temperature. Trial calculations indicate that over most of the operating range of interest, the number of gas-particle collisions are sufficiently large so that this last assumption appears valid. However when the pressure approaches the lower end of the range of interest ( 0.1 to 0.01 torr) this last assuiuption becomes marginal. The desired relation can now be written as,

$$
p_{V}=\left(\frac{1-g-f}{1-g-f+f \alpha}\right) p
$$

Substituting equation (2) and the equation of state for the condensable vapor into the Clausius-Clayperon equation and differentiating yields,

$$
\begin{aligned}
\frac{d p}{p}=\left(\frac{1}{1-g-f}\right) & {\left[\left(\frac{I}{R_{0}}\right)(1-g-f) \frac{d T}{T^{2}}\right.} \\
& \left.+\left(\frac{f \alpha a g}{1-g-f+f \alpha}\right)\right]
\end{aligned}
$$

Momentum Equation

The differential form of the momentum equation can be written as,

$$
\frac{d p}{\psi}=-U d U
$$

Once again, if Dalton's Law is used with the equation of state for each specie and the continuity equation, it is possible to obtain a relation between the stream pressure and density.

$$
\mathrm{p}=(1-\mathrm{g}-f+f \alpha) \frac{\psi \mathrm{R}_{\mathrm{O}} \mathrm{T}}{\boldsymbol{\mu}_{\mathrm{V}}}
$$

Using equation (4) to eliminate $\psi$, one obtains equation (3) in the form

$$
\frac{\mathrm{dp}}{\mathrm{P}}=-\left[\left(\frac{\mu_{\mathrm{V}}}{\mathrm{R}_{\mathrm{O}} \mathrm{T}}\right)\left(\frac{1}{1-\mathrm{g}-\mathrm{f}+\mathrm{f \alpha}}\right)\right] \mathrm{U} \mathrm{dU}
$$

Energy Equation

Carrying out an energy balance between the stagnation chamber and any point in region II results in,

$h_{0}=\frac{{ }^{f} C_{p_{n}} T}{\mu_{n}}+(1-g-f) \frac{C_{p_{V}}{ }^{T}}{\mu_{V}}+g h_{C}+\frac{U^{2}}{2}$

Since, for the particle mass of interest ( $\left.10^{5} \mathrm{amu}\right)$, the random translational rotational and potential energies are negligible, the specific enthalpy of the condensed phase can be written as

$$
\mathrm{h}_{\mathrm{c}}=\frac{\mathrm{C}_{\mathrm{p}_{\mathrm{V}}} \mathrm{T}}{\boldsymbol{\mu}_{\mathrm{V}}}-\mathrm{L}
$$

Substituting this expression into equation

(6) and differentiating yields,

$$
-\mathrm{U} d \mathrm{~d}=\left[\left(\frac{\mathrm{C}_{\mathrm{v}}}{\boldsymbol{a}_{\mathrm{V}}}\right)\left(1-\mathrm{f}+\mathrm{f} \alpha \frac{\mathrm{C}_{\mathrm{p}}}{\mathrm{C}_{\mathrm{p}}}\right)\right] \mathrm{dT}-\frac{\mathrm{L} \mathrm{dg}}{\mathrm{ar}_{\mathrm{v}}}
$$

Particle Formation Efficiency

Equating the right sides of equations (2a) and (5), substituting the expression for $U$ dU from equation (7) into the resulting equation and then rearläiginis,

$$
\begin{aligned}
\alpha\left(\frac{g}{T}\right)=- & (1-f+f \alpha) \frac{d T}{T^{2}}-\frac{R_{O} f \alpha}{L}\left(\frac{d g}{1-g-f}\right) \\
& +\frac{C_{p_{V}}}{L}\left(1-f+f \alpha \frac{C_{p_{n}}}{C_{p_{V}}}\right) \frac{d T}{T}
\end{aligned}
$$

Integrating this equation from the onset of condensation at the saturation point (station 1 in figure 2), to any point in region II yields,

$$
\begin{aligned}
& g-\frac{R_{O} f \alpha}{I} T \ln \left(\frac{1-g-f}{I-f}\right) \\
& =(1-f+f \alpha)\left(1-\frac{T}{T_{I}}\right) \\
& \quad+\frac{C_{p_{V}} T}{I}\left(1-f+f \alpha \frac{C_{p}}{C_{p_{V}}}\right) \ln \frac{T}{T_{I}} .
\end{aligned}
$$

As a check on equation (9) it may be noted that when $f$ is zero, the resulting equation gives the condensation efficiency for a saturated expansion of a single vapor species (ref. 5).

In order to obtain an expression for 
the particle formation efficiency based on stagnation chamber conditions, a few modifications are required. The latent heat can be eliminated by using Troutons rule (ref. 11 ).

$$
I=\frac{92 \beta T_{b}}{v}
$$

the corrective term $B$ is included to account for the fact that some materials deviate slightly from Troutons rule. For most materials, $\beta$ falls in a range between 0.8 and 1.2 .

Using equation (10), the ClausiusClayperon equation, the pressure and temperature relations for an isentropic expansion in region $I$ and the perfect gas relations, equation (9) can be rearranged to yield the desired expression for particle formation efficiency: condensation region, values of $g$ and $\mathrm{T} / \mathrm{T}_{\mathrm{O}}$ must be found that satisfy both equations (11) and (13). In the range of interest, $0<\mathrm{g}<(1-f)$, there is only one set of $g$ and $\mathrm{T} / \mathrm{T}_{\mathrm{O}}$ that simultaneously satisfy both equations (11) and (13).

Since both these equations are transcendental, they are not amendable to direct solution by a simple hand calculation. The Newton-Raphson technique was used here to obtain a computer solution.

\section{IIMITATIONS}

\section{Nozzle Flow Restrictions}

In order for the condensation process to take place, it is necessary that a number of flow restrictions be met. First, acting within the boundary layer are viscous forces that tend to dissipate the di-

$$
\begin{aligned}
& g-\frac{f \alpha \frac{T}{T_{O}}\left[1+\left(\frac{\Gamma-1}{2}\right) M_{S}^{2}\right] \ln \left(\frac{1-g-f}{1-f}\right)}{11.513+11.11 \beta-\ln \left\{\left(\frac{1-f}{1-f+f \alpha}\right)\left[\left(1+\frac{\Gamma-1}{2}\right) M_{S}^{2}\right]^{-\Gamma / \Gamma-1} p_{0}\right\}}=(1-f+f \alpha)\left\{1-\frac{T}{T_{O}}\left[1+\left(\frac{\Gamma-1}{2}\right) M_{S}^{2}\right]\right\}
\end{aligned}
$$

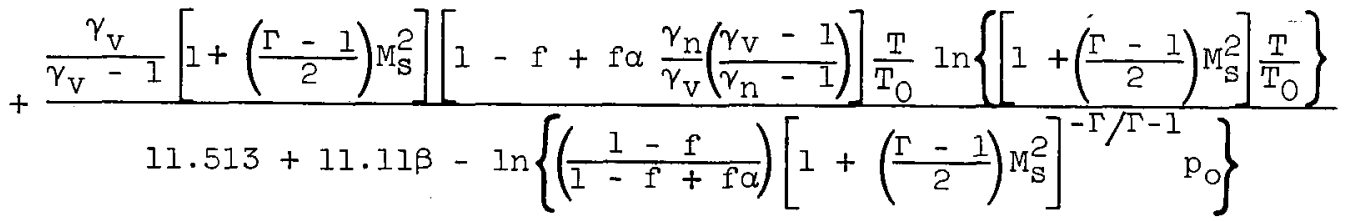

\section{Steam Pressure}

When Trouton's rule (eq. (10)) is used to express the latent heat in the Clausius Clayperon equation (eq. (1)), the resulting integrated equation is

$p_{v}=\exp \left\{-\frac{11.11 \beta T_{b}}{T}+11.513+11.11 \beta\right\}$

Normalizing equation (12) to the condensable vapor pressure at station 1 , then using equation (2) and finally using the equations for an isentropic expansion to express the change in stream properties between the stagnation chamber and station 1 yields

$$
\begin{aligned}
\frac{p}{p_{0}}= & {\left[1+\left(\frac{\Gamma-1}{2}\right) M_{S}^{2}\right]^{-\Gamma / \Gamma-1}\left(\frac{1-f}{1-f+f \alpha}\right) } \\
& \times\left(\frac{1-g-f+f \alpha}{1-g-f}\right) \exp ([11.513+11.11 \beta \\
& -\ln \left\{\left(\frac{1-f}{1-f+f \alpha}\right)\left[1+\left(\frac{\Gamma-1}{2}\right) M_{S}^{2}\right]^{-\Gamma / \Gamma-1}\right. \\
& \left.\times p_{0}\right]\left[1-\frac{T_{0}}{\left.\left.T\left(1+\frac{\Gamma-1}{2} M_{S}^{2}\right)\right]\right)}\right.
\end{aligned}
$$

It should be noted at this point, that to obtain a value for condensation efflclency at any given stream pressure in the rected fluid energy so as to raise the fluid temperature. As a result, if there are any condensed particles in the boundary layer, they may be reevaporated by this viscous heat generation (ref's. 5 and 12). An exact calculation of this effect is mathematically difficult, if not impossible, to aescrive. Theiefore ar approximato approach is used.

As a check to see whether or not the particles can be condensed in the boundary layer under operating conditions of interest for this analysis, the characteristic time for evaporating the particles can be compared with the nozzle residence times. As shown in appendix $B$, this characteristic time is on the order of 10 microseconds. When compared with the nozzle residence times which are on the order of 1 millisecond, it may be reasonably concluded that the condensed particles can be evaporated in the boundary layer.

From the discussion abnve it can he seen that it is desirable to have the boundary layer occupy a small portion of the total nozzle cross sectional area. As a very optimistic estimate of where to cut off the nozzle condensation process due to boundary layer restrictions, that point in the nozzle where the boundary layer completely envelops the flow was chosen (i.e., $\delta / R=1.0)$.

To locate the point in an axisymmetric nozzle where $\delta / R=1$, the empirical equation 


$$
\frac{\delta}{i}=\frac{\mathrm{KM}^{1} \cdot 6}{\sqrt{\mathrm{Re}}}
$$

from reference 13 was used. In order to evaluate $K$, experimental values of $\delta / 2$ were chosen from reference 13, for Reynolds numbers $(200 \leq \operatorname{Re} \leq 7000)$, Mach numbers $(3.5 \leq \mathrm{M} \leq 6 . \overline{0})$ and nozzle pressures (10-2 torr $\leq \mathrm{p} \leq 10^{-1}$ torr) over the range expected in mixed flow colloid thrustors. A value of $K=0.7$ was obtained.

In terms of nozzle radius, equation

(14) can be rewritten as

$$
\frac{\delta}{R}=\frac{0.7\left[\left(\frac{A}{A^{*}}\right)^{1 / 2}-1\right]}{\sin \theta\left(\frac{A}{A^{*}}\right)^{1 / 2}} \frac{M^{1.6}}{\sqrt{R e}}
$$

Since $A / A^{*}, M$ and $R e$ can all be related to the nozzle exit pressure, equation (15) expresses the relation between the normalized boundary layer thickness and the nozzle exit pressure for a fixed set of operating conditions and propellant properties.

As indicated in reference 14 if the flow is in elther the slip or free molecular flow regime there will be a negligible amount of condensation due to the lack of sufficient expansive cooling. If the Knudsen number is used as a criteria for the establishment of continum flow, it is found that continuum flow will take place when the Knudsen number is about $10^{-2}$ or less. Therefore, for the purposes of this analysis, the condensation process was considered to be complete when the stream state points are such that the Knudsen number is on the order of $10^{-2}$. For the mixed-flow condensation process, this was found to be the case when the nozzle exit pressure reached a lower value of about $10^{-1}$ torr.

\section{Space Charge Restriction}

Since the colloid thrustor is an electrostatic device, the maximum flow rate is limited by space-charge effects. Therefore, all operating parameters such as stagnation pressure and nozzle exit pressure must be chosen to be compatible with space charge restrictions. To establish a criteria for the selection of these parameters, the choked flow nozzle equation (ref. 9) is combined with Child's Law for simple diode acceleration (ref. 15), and 1t $1 \mathrm{~s}$ assumed that all the condensable vapor is condensed and all particles are uniformly charged. These assumptions result in the following equation,
As discussed in reference 14, to comply with thrustor operating conditions, the maximum value of $E_{A}$ is about $4 \times 10^{6}$ volts per meter while the minimum value of specific impulse of interest is 2000 seconds. The choice of an applied field strength of $4 \times 10^{6}$ volts/meter was based upon high voltage breakdown data between flat parallel electrodes in vacuum. It is felt that this is a most optomistic choice, since in the presence of charged particles, residual vapor and coolant gas in the colloid thrustor accelerator, the maximum allowable applied electric field will be somewhat lower. In addition, from practical considerations, the maximum value of stagnation temperature is limited to $1500^{\circ} \mathrm{K}$. Increasing this temperature as high as $2000^{\circ} \mathrm{K}$ makes little difference in the qualitative results. In order to meet space charge re-. strictions in an accelerator system, $\dot{m}_{\mathrm{Sc}} \geq \dot{\mathrm{m}}_{\mathrm{f}}$. Therefore, the thrustor operating conditions and propellant properties must be chosen so that the right side of equation (16) is always equal to or greater than one.

\section{RESULTS AND DISCUSSION}

As can be seen in equations (11) and (13), there are an extremely large number of propellant properties and nozzle operating conditions that can be varied to evaluate the particle formation efficiency. A number of these parameters, however, can be preselected based upon qualitative physical reasoning. Hydrogen was chosen as a coolant gas because it has the largest heat capacity. The large heat capacity is desirable because the amount of material that will condense is limited by the heat capacity of the stream. The coolant gas can represent as much as $75 \%$ of the stream heat capacity in cases of interest.

The choice of the value for Mach number at the saturation point for the condensable vapor, $\mathrm{M}_{\mathrm{S}}$, is based upon two conditions. It is desirable to choose $M_{S}$ large enough so that the effects of thermal choking can be avoided. (As a result of thermal choking, all the material previously condensed can evaporate (ref. 5). Sample calculations for a mixed flow saturated expansion indicate that when

$\mathrm{M}_{\mathrm{S}} \geq 1.1$ thermal choking can be effectively avoided. If $\mathrm{M}_{\mathrm{S}}$ is increased beyond a value of 1.1 for fixed stagnation and nozzle exit pressure, the particle formation efficiency w111 drop since the actual condensation process will occur over a lower expansion ratio. Therefore a value of $M_{S}=1.1$ is used as a limit.

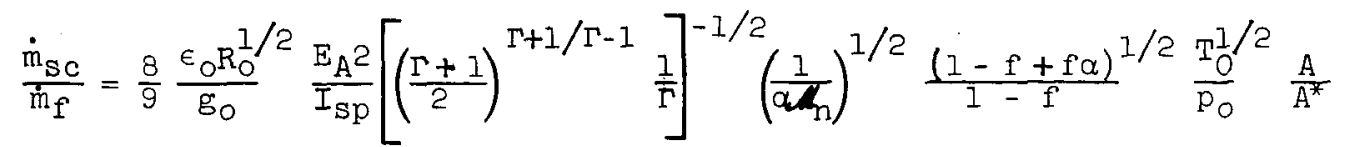


Plotted in figures $3(a)$ and $(b)$ is the particle formation efficiency as a function of the fractional flow rate of coolant gas. Treated as a parameter in $\mathrm{fig}-$ ure 3 , is stagnation pressure. As the value of the stagnation pressure increases from 1 to 100 torr, the maximum value of $g$ increases from about 54 to $87 \%$ while the optimum value of coolant gas flow rate drops from about 42 to $11 \%$. It should be noted that these curves were drawn for fixed values of $\epsilon=0.8, \alpha=30, \gamma_{v}=1.67$, and $p_{e}=0.1$ torr. It was found that increasing $\epsilon$ as high as 1.2 and dropping $\gamma_{\mathrm{V}}$ as low as 1.3 tended to decrease the values of $g$ for all cases to a slight degree. Varying $\alpha$ and $p_{e}$ had much more of a pronounced effect on the particle formation efficiency. Shown in figure $3(b)$ is the effect of decreasing the nozzle exit pressure to 0.01 torr. For this case it can be seen that the maximum value of particle formation efficlency for $\mathrm{p}_{\mathrm{O}}=100$ torr is now about 90\% while that for 1 torr is about 78\%. Thus, as might be expected, the particle formation efficiency increases with a decrease in nozzle exit pressure (all other parameters held fixed) due to the increased stream expansion. Although not shown in figure 3 , increasing $\alpha$ tends to increase the values of particle formation efficiency. For example, for a stagnation pressure of 1 torr, a nozzle exit pressure of 0.01 torr and for values of other parameters as indicated in figure $3(b)$, the maximum values of particle formation efficiency are about $90 \%$ and $58 \%$ for values of $\alpha$ of 100 and 10 , respectively. Thus, if $p_{0}$ and $\alpha$ are chosen high enough and $p_{e}$ chosen low enough, any desired value of particle formation efficiency should be attalnable with no other constraints piaced upon ine system.

For the case of a mixed flow collold thrustor, however, there are a number of restrictions that must be met, as pointed out previously. Shown in figure 4 is a plot of $\delta / R$ as a function of nozzle exit pressure. Once again $p_{0}$ is treated as a parametric variable. Furthermore, this curve was drawn for the fixed values $f^{\prime}=0.3, \epsilon=0.8, \alpha=30$. It $c$ an be seen from figure 4 as the stagnation pressure increases from 1 to 100 torr, the minimum allowable nozzle exit pressure increases from about 0.1 torr to 0.6 torr. Stagnation pressures below 1 torr are of no intcrost since the nozzle flow is no longer in the continuum regime. Experimental evidence (ref. 14) indicates that there is a negligible amount of condensation when the flow is either in the transition or free molecular flow regimes. For those cases where the particle formation efficiency is greater than $50 \%$, there is no significant drop in the minimum allowable nozzle exit pressure for variations in $\epsilon$, $f$, and $\alpha$ around the values used in obtaining figure 4 . Therefore, it may be concluded that, due to the boundary layer restriction, the minimum allowable nozzle exit pressure is on the order of 0.1 torr.
The effect of the space charge restriction on nozzle exit pressure is shown in figure 5. This figure is plotted for the fixed values $f=0.3, \epsilon=0.8$, and $\alpha=30$. From this figure it can be seen that for stagnation pressures between $l$ and 10 torr, the maximum allowable nozzle exit pressure is on the order of 0.01 torr. Increasing the stagnation pressure beyond 10 torr, drops the maximum allowable exit pressure well into the 0.001 torr range. To match the boundary layer restriction the highest possible nozzle exit pressure is, of course, desired. If the value $\alpha=30$ is held constant and both $\epsilon$ and $f$ varied over wide ranges, the position of the curves in figure 5 do not significantly change. When $\alpha$ is increased above 30 the curves tend to drop to lower values, which is in the wrong direction as previously pointed out. As $\alpha$ is decreased below 30 , the curves tend to rise, however if a falls much below 10, the particle formation efficiency is less than $50 \%$. In general, it may be concluded that when $10<\alpha<50$ and $1 \leqslant p_{0} \lesssim 10$, the maximum alilowãble nozzle exit pressure due to space charge restrictions is on the order of 0.01 torr and the particle formation efficiency is limited to about $80 \%$.

Another interesting result that can be obtained from the space charge restriction is that of the choice of a suitable coolant gas. As was stated previously, hydrogen is desired as a coolant gas due to its relatively high heat capacity. Also, equation (16) shows that the ratio $\dot{\mathrm{m}}_{\mathrm{Sc}} / \dot{\mathrm{m}}_{\mathrm{f}}$ varies inversely as the square root of the molecular weight of the coolant gas. Increasing the weight much beyond a factor of 2 would tend to drastically drop the curves shown in figure 5. As a result, the maximum allowable nozzle exit pressure due to space charge restrictions would shift to much lower values than $10^{-2}$ torr. With hydrogen as a propellant, the minimum allow$a b l e$ nozzle exit pressure due to boundary layer restrictions is about 0.10 torr. Therefore by going to coolant gases with molecular weights much higher than that of hydrogen, an already difficult nozzle exit matching problem would become even more severe.

Finally, shown in figure 6 is the particle formation efficiency using the physlcal properties of three possible propellants representing about an order of magnitude variation in molecular weight. In all cases the particle formation efficiency is plotted as a function of the fractiondi flow of hydrogen coolant gas. Shown in figure 6(a) is a lightweight propellant (lithium), in figure $6(\mathrm{~b})$ is a medium weight propellant (sodium), and in figure $6(c)$ a heavy propellant (zinc). Comparing figures 6(a) through (c), as the propellant molecular weight increases, the particle formation efficiency also increases.

In all cases these three specific propellants examined encountered the same problems as the other general propellants previously examined in figures 3,4 , and 5 , namely, it was not possible to match the minimum allowable nozzle exit pressure due 
to boundary layer restrictions ( 0.1 torr) with the maximum allowable pressure due to space charge restrictions (0.01 torr).

\section{CONCLUDING REMARKS}

Over a wide range of operating conditions, propellants, and coolant gases, it was found that particle formation efficiency was virtually unlimited. However for cases applicable to colloid thrustors where the particle formation efficiencies were greater than $50 \%$, the minimum allowable nozzle exit pressure due to boundary layer and non-continuum flow effects were about 0.1 torr, while at the same time the maximum allowable nozzle exit pressure due to space charge effects was about 0.01 torr. Thus unique techniques to match the boundary layer and continuum flow limits with the space charge restriction appear necessary. Expanding the colloid beam beyond the nozzle exit prior to entering the accelerator region appears to be impractical.

A area, $\mathrm{m}^{2}$

\section{APPENDIX A}

$\mathrm{C}_{\mathrm{p}}$ specific heat at constant pressure, joules/kg

$\mathrm{E}_{\mathrm{a}}$ applied electrostatic field, $\mathrm{v} / \mathrm{m}$

$\boldsymbol{\epsilon}_{\mathrm{e}}$ reevaporation energy per unit volume, joules $/ \mathrm{m}^{3}$

$\dot{\boldsymbol{f}}_{\mathrm{f}}$ frictional energy per unit volume per unit time, joules $/ \mathrm{m}^{3}-\mathrm{sec}$

$f$ fractional mass flow of coolant gas

$g$ particle formation efficiency

go acceleration due to gravity on earth's surface, $\mathrm{m} / \mathrm{sec}^{2}$

h specific enthalpy, joules $/ \mathrm{m}^{3}$

$I_{\text {Sp }}$ specific impuise, sec

$K \quad$ constant

I latent heat of vaporization, joules $/ \mathrm{kg}$

$\imath$ axial length of nozzle downstream of throat, $m$

M Mach number

* molecular weight, $\mathrm{kg} / \mathrm{kg}$-mole

$\dot{\mathrm{m}}$ mass flow rate, $\mathrm{kg} / \mathrm{sec}$

$\mathrm{p}$ pressure, $\mathrm{n} / \mathrm{m}^{2}$

$\mathrm{R}$ radial distance to nozzle wall from nozzle axis; $m$

Re Reynolds number based on axial length

$\mathrm{R}_{\mathrm{O}}$ gas constant, joules/mole- $\mathrm{O}_{\mathrm{K}}$

$r$ radial distance from nozzle axis, $m$

$\mathrm{T}$ temperature, ${ }^{\circ} \mathrm{K}$

U directed velocity, $\mathrm{m} / \mathrm{sec}$

$U_{a}$ directed velocity along nozzle axis, $\mathrm{m} / \mathrm{sec}$

$\mathrm{x}$ distance, $\mathrm{m}$

$\alpha$ ratio of condensable vapor to coolant gas molecular weight $\beta$ ratio of actual latent heat to that predicted by Trouton's rule

$\gamma$ gaseous specific neat ratio

o boundary layer thickness, $m$

$\epsilon_{0}$ permitivity of free space,

$8.85 \times 10^{-12} \mathrm{c}^{2} / \mathrm{nm}^{2}$

$\eta \quad$ viscosity coefficient, $n s e c / m^{2}$

$\theta$ nozzle expansion half angle, deg

$\rho$ density, $\mathrm{kg} / \mathrm{m}^{3}$

$\tau$ time, sec

$\Psi$ total dispersed density of mixture, $\mathrm{kg} / \mathrm{m}^{3}$

\section{Subscripts}

C condensed phase

f nozzle flow

n noncondensable coolant gas

- stagnation chamber

s saturated state at station 1

sc space charge

$\checkmark$ condensable vapor

\section{Superscript}

* nozzle throat

\section{$\underline{\text { APPENDIX B }}$}

The characteristic reevaporation time is defined as

$$
\tau=\frac{\mathscr{\epsilon}_{\mathrm{e}}}{\dot{\boldsymbol{\varepsilon}}_{\mathrm{f}}}
$$

where $\boldsymbol{b}_{\text {e }}$ is the energy per unit volume required to completely reevaporate the condensed particles and $\dot{\delta}_{f}$ is the energy dissipated per unit time per unit volume by the frictinnal forces. For steady state flow of a newtonian fluid in an adiabatic nozzle,

$\dot{\boldsymbol{\varepsilon}}_{\mathrm{f}}=\sum_{i \mathrm{~K}}\left[\eta\left(\frac{\partial U_{i}}{\partial \mathrm{x}_{K}}+\frac{\partial U_{K}}{\partial x_{i}}-\frac{2}{3} \delta_{i K} \frac{\partial U_{l}}{\partial x_{l}}\right)\right] \frac{\partial U_{i}}{\partial x_{K}}$

This equation, which was obtained by manipulation of the Navier-Stokes, continuity and energy equations, is similar in form to that given in reference 16. In order to evaluate equation (BI), it is necessary to know the spatial fluid velocity distriiution.

Since, over the operating conditions of interest, the Reynolds number for the mixed flow colloid thrustor nozzle is so low $(5000 \leq \mathrm{Re})$, the flow can be treated as laminar. If the magnitude of the fluid velocity is assumed to vary parabolically with radial distance from the nozzle axis,

$$
\dot{\boldsymbol{\theta}}_{\mathrm{f}}=\frac{4 \pi U_{\mathrm{a}}^{2} r^{2}}{\mathrm{R}^{4}}
$$

In general, for laminar flow through an axisymmetric duct, a parabolic velocity 
distribution occurs when the boundary layer completely envelops the nozzle. For the purposes of this analysis, it is assumed that no appreciable change in the particle formation process occurred due to frictional energy dissipation until this condition was reached. (This assumption yields an optimistic value of condensation efficiency.)

Combining the expression for the volumetric energy required to completely evaporate the condensed particles at any given point in the nozzle,

$$
\mathscr{\varepsilon}_{e}=\psi g I
$$

with equation (B2), results in the desired relation

$$
\tau=\frac{4 \eta U_{\mathrm{a}}^{2} r^{2}}{\psi g I R^{4}}
$$

When equation (20) is evaluated over the range of propellant properties and operating conditions of interest, the characteristic times to completely evaporate the condensed particles is on the order of 10 microseconds. The nozzle sizes chosen for this calculation corresponded to thrustor power levels as high as 104 watts and specific impulse levels as low as 2000 seconds. Increasing the power level to as high as $10^{\frac{6}{6}}$ watts does not qualitatively change these results.

\section{REFERENCES}

(1) Goldin, D. S. and Kvitek, G. L., "An analysis of particle formation efficiency in a colloid thrustor," AIAA Paper 66-253 (March 1966).

(2) Mickelsen, W. R., "Electric propulsion," Space/Aeronautics 1964/1965 Research and Develupmeit Techinfal Hand book 42, 50-53 (1964).

(3) Von Ohain, H. J. P., Iawson, M. O., and Hasinger, S. H., "Gas cooled colloid propulsion systems," United States Patent number 3, 217, 488 (November 1965).

(4) Courtney, W. G., "Kinetics of condensation from the vapor phase," Texaco Experiment Inc. Report No. TM-1340 (July $1962)$.

(5) Wegener, P. P. and Mack, I. M., "Condensation in supersonic and hypersonic wind tunnels," Advances In Applied Mechanics, H. L. Dryden and Th. von Kármán, eds. vol. 5 (Academic Press, New York, 1958), 307-117.

(6) Cox, A. L., "Particle growth in the Ionic nucleation condensation colloldal Ion source," Brown Engineering Co. Technical Note R-139 (March 1965).

(7) Merritt, G. E. and Weatherston, R. C., "Condensation of mercury vapor and drop growth processes in a nitrogen flow," AIAA Paper 66-85 (January 1966).

(8) Mickelsen, W. R. and Kaufman, H. R., "Status of electrostatic thrustors for space propulsion," NASA TN D-2172 (May 1964).

(9) Obert, E. F., Thermodynamics (McGrawHill Book Co., Inc., 1948).
(10) Owen, J. M. and Sherman, F. S., "Design and testing of a mach 4 axially symmetric nozzle for rarefied gas flow," University of California Report He-150-104 (July 1952).

(11) Perry, J.H., ed., Chemical Engineers' Handbook (McGraw-Hill Book Co., Inc., New York, and ed., 1941).

(12) Wegener, P., Reed, S., Jr., Stollenwerk E., and Lundquist, G., "Air condensation in hypersonic flow," $\mathrm{J}$. Appl. Phys. 22, 1077-1083 (1951).

(13) Touryan, K. J. and Drake, R. M., "Flow investigations in Delaval supersonic nozzles at very low pressures," Rarefied Gas Dynamics, J. A. Laurmann, ed., vol. 2 (Academic Press, New York, 1963) 402-434.

(14) Norgren, C. T. and Goldin, D. S., "Experimental analysis of the exhaust beam from a colloid thrustor," AIAA J. 3, 1943-1945 (1965).

(15) Cobine, J. D., Gaseous Conductors (Dover Publications, Inc., New York, 1958).

(16) Landau, I. D. and Lifshitz, E. M., Fluid Mechanics (Addison-Wesley Publishing Co., Reading, Mass., 1959). 


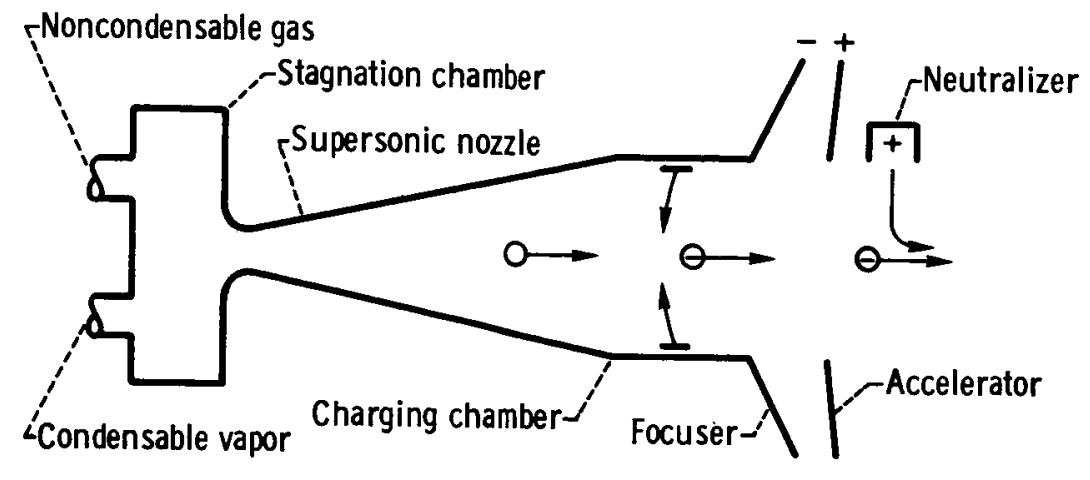

Figure 1. - Schematic of a mixed-flow condensation type colloid thrustor. 


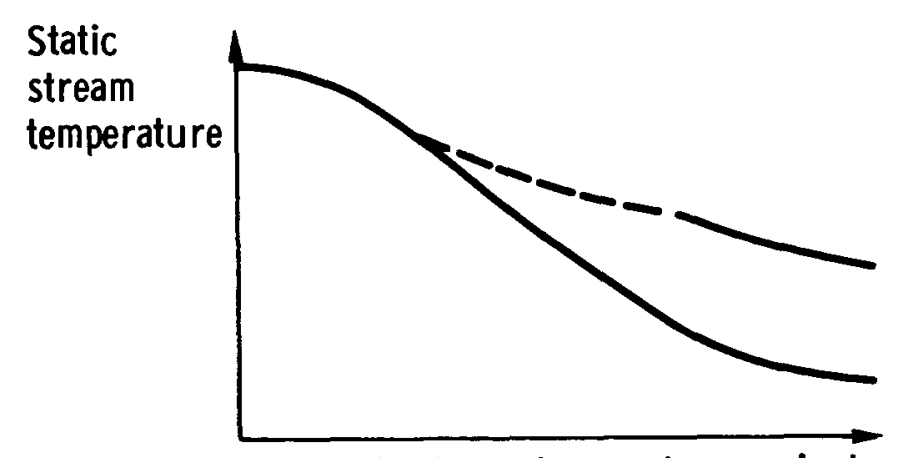

(a) Static stream temperature against axial distance.

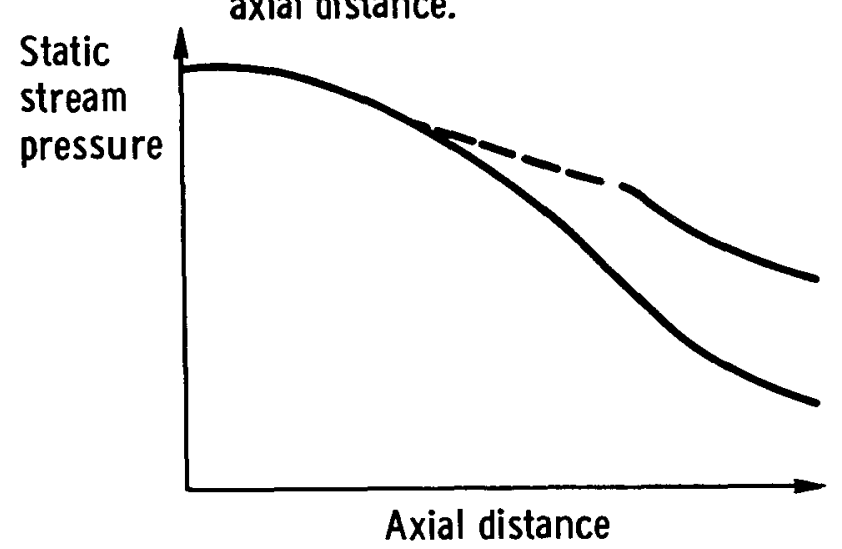

(i) Static stream pressure against axial distance.

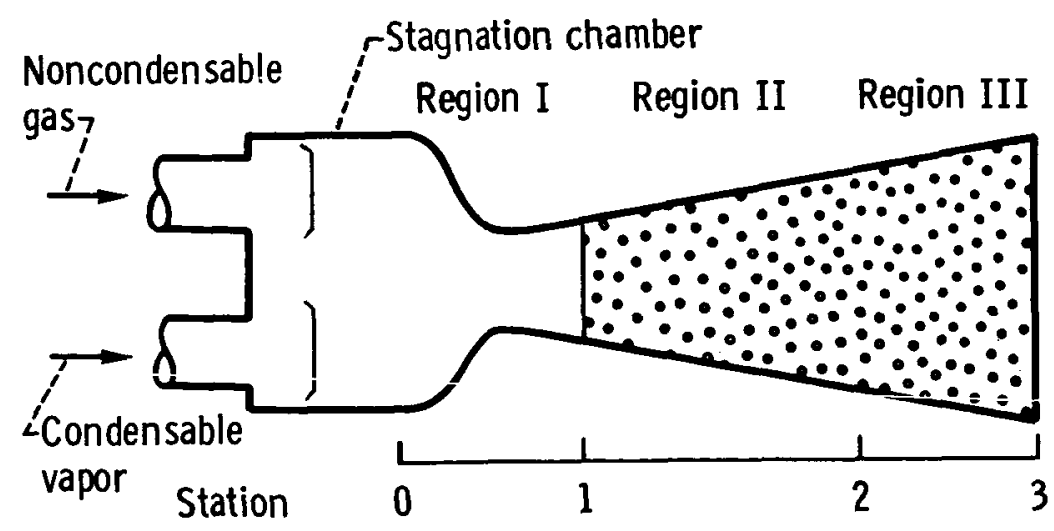

(c) Particle generator.

Figure 2. - Schematic description of the particle formation process in a mixed-flow, condensation type colloid thrustor. 


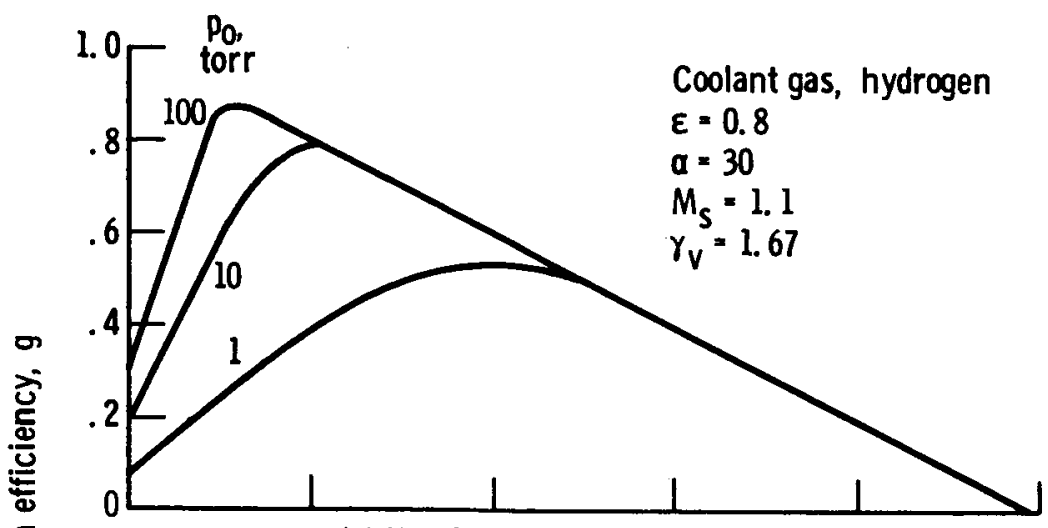

(a) Nozzle exit pressure, 0.1 torr.

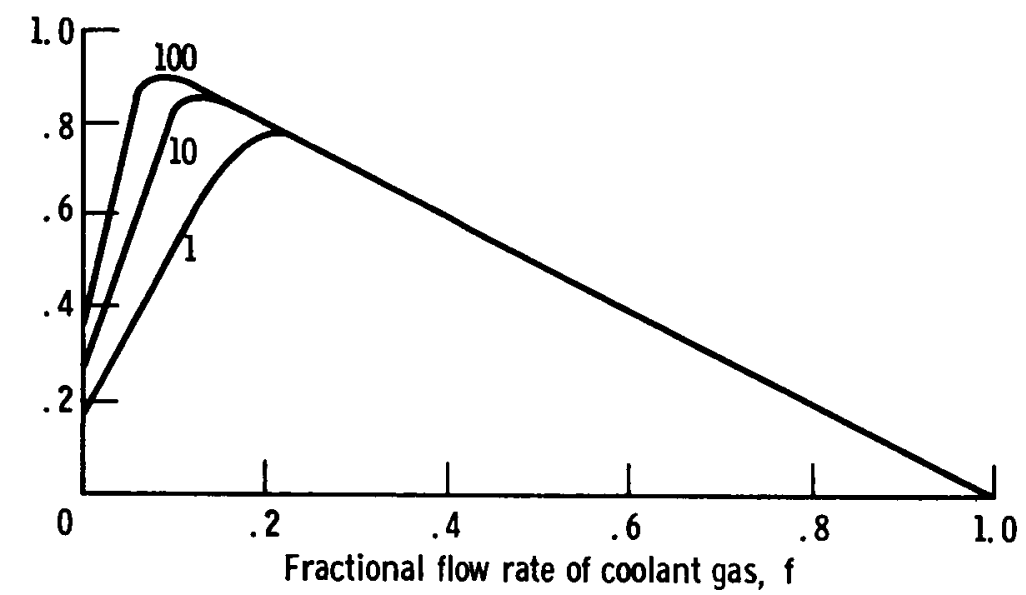

(b) Nozzle exit pressure, 0.01 torr.

Figure 3. - Particle formation efficiency as a function of fractional flow rate of coolant gas.

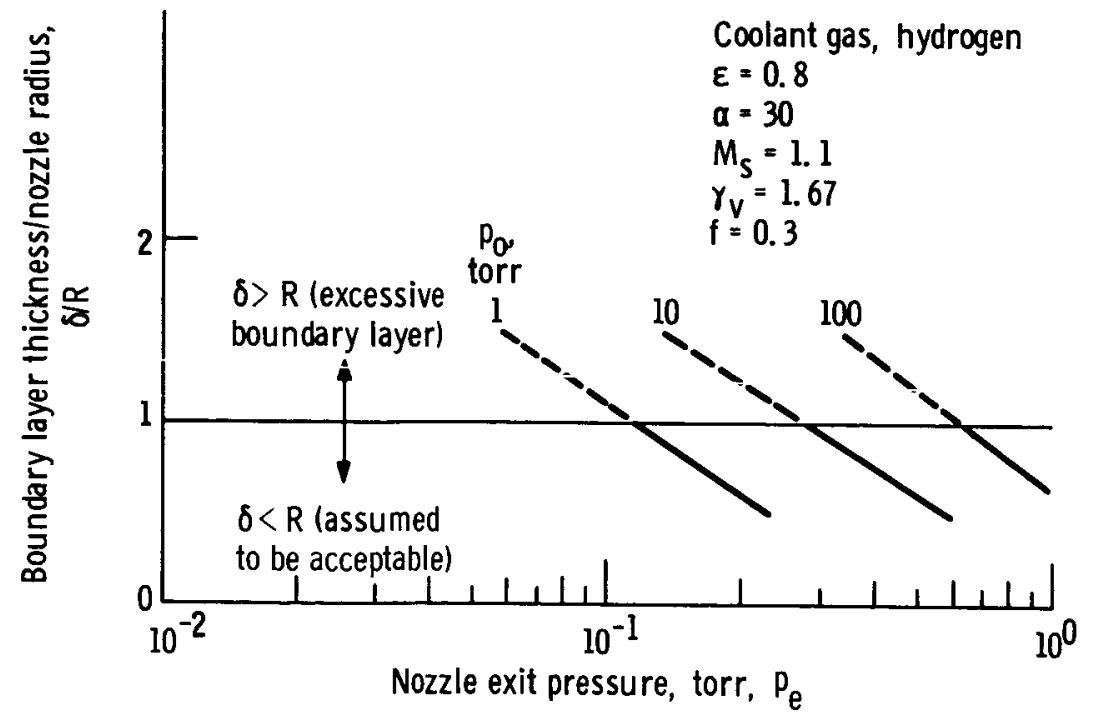

Figure 4. - Effect of boundary layer restriction on nozzle exit pressure. 


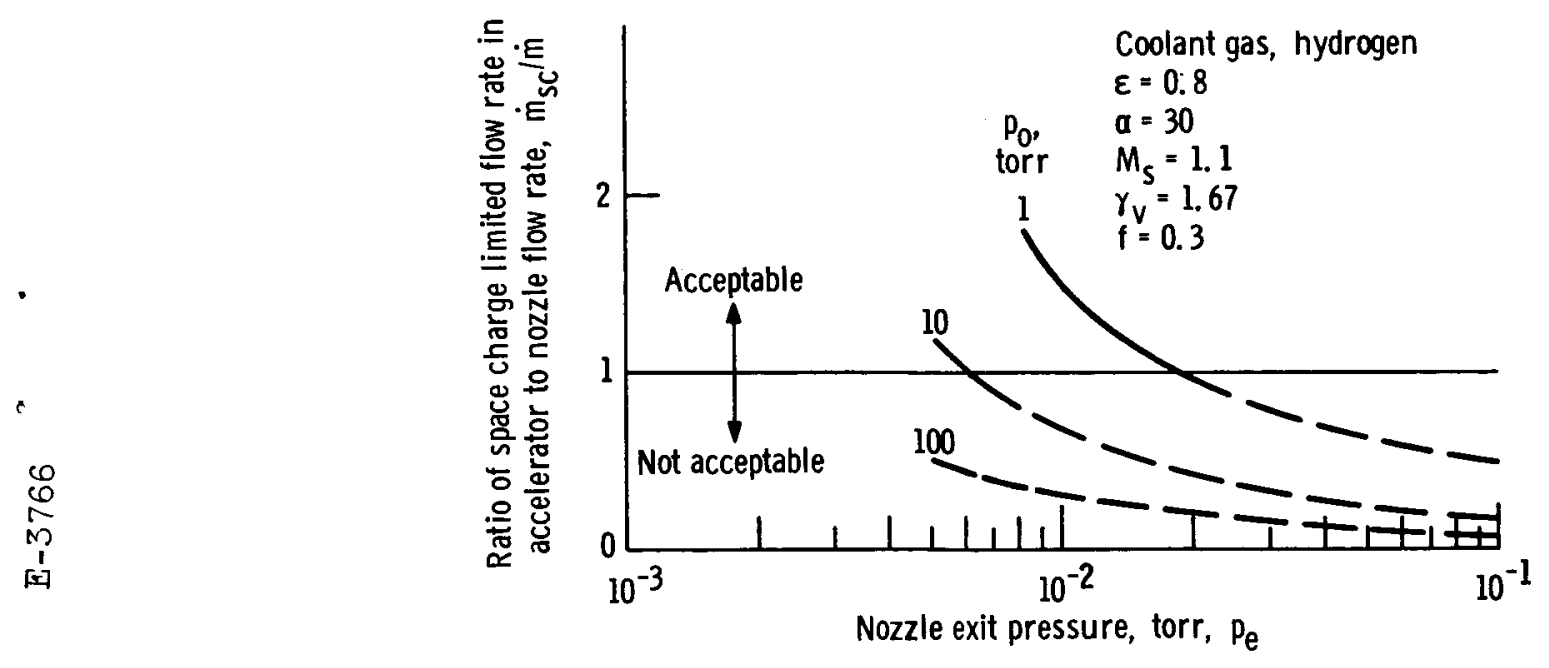

Figure 5. - Effect of space charge restriction on nozzle exit pressure.

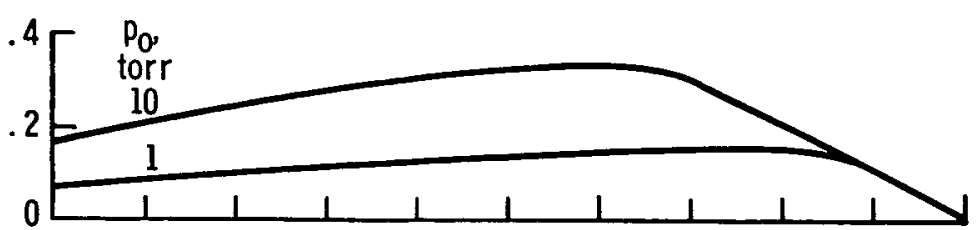

(a) Lithium propellant.

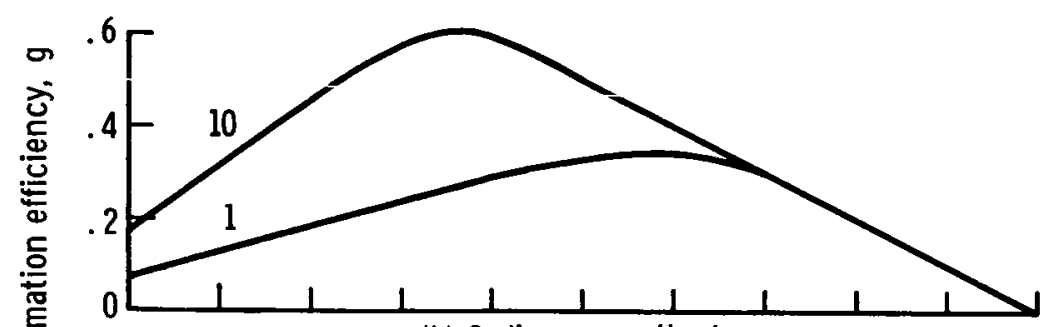

(b) Sodium propellant.

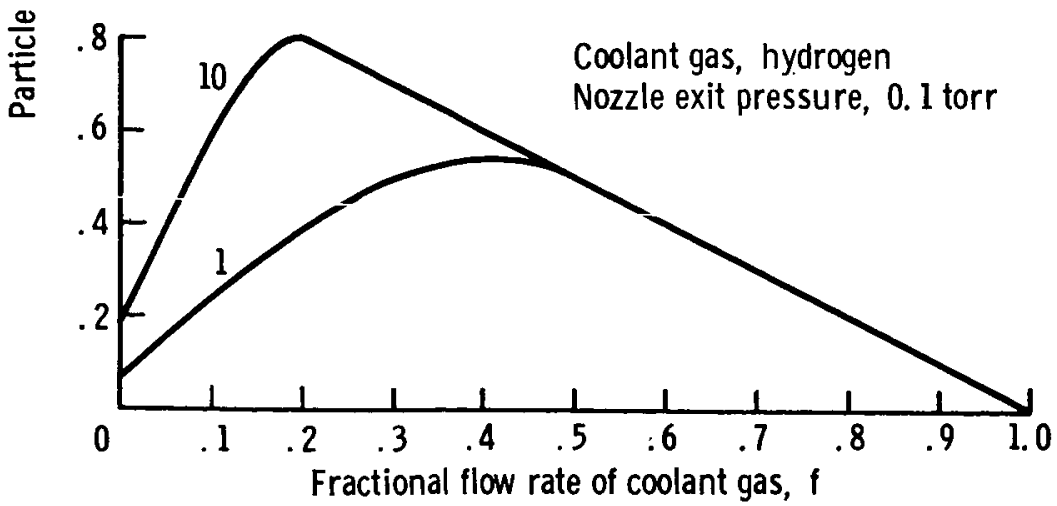

(c) Zinc propellant.

Figure 6. - Particle formation efficiency for a mixed flow colloid thrustor. 